\title{
Trends in utilization and off-label use of polyethylene glycol 4000 laxatives and the prevalence of constipation in children in France
}

This article was published in the following Dove Press journal:

Clinical and Experimental Gastroenterology

27 July $201 \mathrm{I}$

Number of times this article has been viewed

\author{
Nawab Qizilbash',2 \\ Ignacio Mendez' \\ 'OXON Epidemiology, Madrid, \\ Spain, and London, UK; ${ }^{2}$ Department \\ of Primary Care and Social Medicine, \\ Imperial College, London \\ University, UK
}

Purpose: To determine trends in utilization and off-label use of polyethylene glycol (PEG) 4000 in children and to determine the prevalence of constipation.

Methods: Retrospective cross-sectional analyses were conducted from 1997 to 2007 in a French health care database comprising general practitioners and pediatricians. Patients prescribed PEG 4000 (Forlax ${ }^{\circledR}$; Ipsen Pharma, Paris, France) were used to assess PEG 4000 use; constipation was defined by a diagnosis of constipation or use of any laxative. Analyses used linear regression models to fit trends over time.

Results: The study sample consisted of a nationally representative sample of 1200 general practitioners with 1.6 million patient medical records and 100 pediatricians with 70,000 patient medical records. Data were available from 1997 to 2007 for general practitioners and from 2003 to 2007 for pediatricians and were extrapolated to the national level. Among both groups of physicians there were statistically significant increases in the number of patients prescribed $4 \mathrm{~g}$. For the $10 \mathrm{~g}$ dose, there was a decline among pediatricians. The largest increases were in children aged $0-8$ years and in females. The prevalence of constipation in children aged $0-18$ years was $4 \%$.

Conclusion: There has been an increase in the use of PEG 4000 laxative in children, particularly in the younger ages and in females. Use of the $4 \mathrm{~g}$ dose has increased. There was considerable off-label use of PEG 4000 in children aged $0-8$ years before the introduction of the $4 \mathrm{~g}$ pediatric dose, which reflected clinical need.

Keywords: polyethylene glycol, macrogol 4000, children, drug utilization, database, laxative, off-label use, prevalence, constipation, time trends

\section{Introduction}

Constipation in children is a common condition. ${ }^{1}$ The prevalence of constipation varies from $1 \%$ to $30 \%$ depending on the diagnostic methodology employed, the sampling frames, and the populations sampled. ${ }^{2}$ The prevalence of constipation over time is uncertain $^{3}$ and few population-based studies exist in the literature.

The lack of studies on constipation in children, despite its high prevalence, may be due to a view that constipation is something that children "grow out of." However, a long-term follow-up study of chronically constipated children found that in a third of their subjects, complaints of constipation persisted into young adulthood. ${ }^{4}$ Approximately $50 \%$ of the children also experienced at least one relapse within the first 5 years after initial successful treatment. ${ }^{4}$ After intensive medical and/or psychosocial treatment, a subgroup of children with persistent constipation will have an unsuccessful outcome, necessitating surgical intervention (eg, cecostomy). ${ }^{5}$ Constipation also causes
Correspondence: Nawab Qizilbash OXON Epidemiology, 200 Northcote Road, London EI77DH, UK

$\mathrm{Tel}+44629846059$

Fax +442085090334

Email n.qizilbash@oxonepi.com 
physical and emotional distress and is associated with a significantly decreased quality of life, another factor arguing against the problem's supposedly benign nature. ${ }^{6}$

More studies have been conducted on the population prevalence of constipation in adults, with report rates that range from $2 \%$ to $28 \%{ }^{7-14} \mathrm{~A}$ recent study of a questionnairebased assessment of constipation in nationally representative samples of subjects found France to have the highest prevalence of constipation (14.0\%) among the other European countries in the study (the prevalence rates for Germany, Italy, and the UK were $5.4 \%, 8.0 \%$, and $7.7 \%$, respectively). ${ }^{15}$ For French subjects under age 30 years (no lower age limit was reported in the study), the prevalence was $12 \% .^{15}$

The use of laxatives is not well documented, although a few studies in the USA indicate that it is considerable in children, with a heavy medical cost burden that is increasing over time. ${ }^{3,16}$ In the USA, the use of laxatives is greater in children and is increasing. ${ }^{3}$ The increase in laxative use from 1997 to 2006 was predominantly among hyperosmolar laxatives. ${ }^{16} \mathrm{~A}$ multicountry cross-sectional survey documented laxative use but could not differentiate the types of laxatives used. ${ }^{14}$ Additionally, there is a suspicion that off-label use of PEGs was common due to the clinical need for laxatives in younger children until the approval of agents specifically for them. ${ }^{17}$

Few data are available in Europe on laxative use. However, in France, where constipation has a higher reported prevalence than in many other EU countries, ${ }^{15}$ a large health care database was available to obtain these data (see Methods). Therefore, the current study was conducted in children in France to:

- quantify the degree of use of hyperosmolar laxatives, such as polyethylene glycol (PEG) 4000 and to test whether PEG laxative use has increased over time

- describe and quantify time trends in use

- describe and quantify the degree of off-label use

- examine the influence of the introduction of a pediatric dose on prescription trends

- determine the prevalence of constipation in children in France.

Forlax $^{\circledR}$ (Ipsen Pharma, Paris, France), a 4000 molecular weight macrogol PEG without electrolytes, is considered to be a frequently used PEG for constipation in France and was used to reflect patterns of hyperosmolar PEG laxative use in that country. It is packaged in two doses, $4 \mathrm{~g}$ and $10 \mathrm{~g}$. In France, the $10 \mathrm{~g}$ dose was approved in 1995 for adults and children aged $>8$ years. The $4 \mathrm{~g}$ dose was approved for children from age 6 months to 8 years and launched in July $2005,{ }^{3,16}$ thus allowing the quantification of the off-label use of Forlax to be feasible. Therefore, to track changes over time, the analysis used this particular trade-named product as a measure of PEG 4000 use for constipation in children.

\section{Methods}

This study was a retrospective cross-sectional observational study in the Longitudinal Patient Database (LPD), a database used by general practitioners and pediatricians in France over the period 1997 to 2007, held by the market research company Cegedim Strategic Data, France. The general practitioners and office-based pediatricians forming the panel of physicians for the study used clinical management software in their daily practice. The office-based active general practitioners and pediatricians uploaded anonymous and coded excerpts from the medical files of patients who had consulted them. The representativeness of the panel of physicians reflected France based on age, gender, and geography. Data items included: age, gender, medical history (event dates, diagnoses, risk factors, referrals to specialists), therapeutic history (date/ length of prescription, molecule/product, dose), additional information (test results, immunizations, height, weight, blood pressure), and date of data input.

For assessing hyperosmolar PEG laxative use, this study used patients prescribed the PEG 4000 product tradenamed Forlax as a measure of hyperosmolar PEG laxative use in France from 1997 to 2007. Inclusion criteria for the study included a prescription of Forlax at doses of $4 \mathrm{~g}$ and $10 \mathrm{~g}$ in subjects aged $0-18$ years, at least once in each relevant year, from January 1, 1997 to December 31, 2007. Inclusion criteria for identifying constipation was one or more prescriptions of any laxative or enema (Code A06A of the Anatomical Therapeutic Classification [ATC]) or an assignment of a diagnosis of constipation in subjects aged 0-18 years between January 1, 1997 and December 31, 2007. As the data have already been collected and are totally anonymous, no ethical approval was required in France to conduct the analysis.

Statistical analysis used descriptive measures of binary data with total numbers and frequencies. The base population for the calculation of drug utilization in each year comprised patients aged $0-18$ years prescribed Forlax $4 \mathrm{~g}$ and $10 \mathrm{~g}$ by general practitioners and pediatricians. The base population for the calculation of prevalence in 2007 comprised patients aged $0-18$ years who had consulted general practitioners and/or pediatricians. Analyses used gender and the age groups $0-18,9-18$, and $0-8$ years. Hypothesis testing was conducted 
to examine for statistically significant increases with time in utilization and to quantify the trends. Time trends in patients prescribed PEG 4000 were analyzed by linear regression techniques following the ordinary least squares technique after the transformation of data, if required. Where a linear model was clearly inappropriate from inspection of the graphical plot of the data, an exponential model with transformation of the data using a logarithmic function was employed. Regression values are displayed using the beta coefficient, the standard error, the proportion of the variability of the data fitted by the model $\left(\mathrm{R}^{2}\right)$ and statistical significance with $P$ values. The Stata statistical package (Stata IC v 11; Stata Corp, College Station, TX) was used to conduct the analysis.

\section{Results}

The study sample consisted of 1200 general practitioners from a total of approximately 56,000 with 12.8 million children nationally who consulted them at least once in the relevant year, and 100 pediatricians from a total of approximately 2670. Data were available from 1997 to 2007 for general practitioners and from 2003 to 2007 for pediatricians. The general practitioners were representative of French general practitioners according to the criteria of age, gender, and geographical region (Table 1). The results from the sample in the study were extrapolated to the national level for France based on the number of subjects in the study population and are presented nationally.

Among general practitioners, there was an absolute increase in patients aged $0-18$ years prescribed both doses of PEG 4000 during the period 1997 to 2007, with 15,002 patients in 1997 and 133,952 patients in 2007 (test of trend

Table I Comparison of general practitioners in the study sample and nationally in France

\begin{tabular}{lll}
\hline Variable & Study sample & France nationally \\
\hline $\begin{array}{ll}\text { Age of physician } \\
<4 I\end{array}$ & $9.8 \%$ & $9.6 \%$ \\
$4 I-45$ & $14.2 \%$ & $14.3 \%$ \\
$46-50$ & $22.7 \%$ & $22.3 \%$ \\
$5 I+$ & $53.4 \%$ & $53.9 \%$ \\
Gender & & \\
Male & $78.3 \%$ & $74.7 \%$ \\
Female & $21.8 \%$ & $25.3 \%$ \\
Region of France & & \\
West & $18.1 \%$ & $18.0 \%$ \\
Paris Region & $19.6 \%$ & $16.2 \%$ \\
South West & $15.0 \%$ & $15.4 \%$ \\
Central East & $13.3 \%$ & $13.9 \%$ \\
South West & $9.5 \%$ & $10.9 \%$ \\
North & $9.3 \%$ & $9.7 \%$ \\
East & $8.3 \%$ & $8.8 \%$ \\
Central West & $6.9 \%$ & $7.2 \%$ \\
\hline
\end{tabular}

$P<0.001$; see Table 2 and Figure 1). The increase was gradual in older children aged 9-18 years: from 14,015 patients in 1997 to 2005 to an abrupt increase to 60,194 patients in 2007 (test of trend $P<0.001$ ) (Figure 1). The increase was initially less steep in younger children aged $0-8$ years, with 987 patients in 1997 and 10,557 patients in 2004, followed by an abrupt increase to 32,799 patients in 2005 and rising to 73,759 patients in 2007 (test of trend $P<0.001$, Figure 1). The relative proportion of patients prescribed PEG 4000 in the 9-18 years age group declined from $93.4 \%$ in 1997 to $44.9 \%$ in 2007, while the proportion of patients in the $0-8$ year age group increased from $6.6 \%$ in 1997 to $55.1 \%$ in 2007 .

A statistically significant trend $(P<0.001)$ described the pattern of increase in patients prescribed the $10 \mathrm{~g}$ dose, which rose from 15,002 in 1997 to 47,053 in 2007 (Figure 2). The $4 \mathrm{~g}$ dose recorded 0 patients from 1997 to 2004, with a subsequent increase reaching 88,454 in 2007 (Figure 2). However, the trend was not statistically significant with either a simple linear or exponential model (Figure 2). The proportion of female patients prescribed the $10 \mathrm{~g}$ dose was greater than the proportion of males (increment per year of 1839 female patients prescribed compared with 1129 males, both statistically significant) and for the $4 \mathrm{~g}$ dose the linear increment per year was 18,409 females compared with 14,839 males, both statistically significant. The proportion of female patients prescribed the $10 \mathrm{~g}$ dose declined from $70.4 \%$ in 1997 to $62.9 \%$ in 2007. The proportion of female patients prescribed the $4 \mathrm{~g}$ dose was fairly static at approximately 57\% between 2005 and 2007.

Among pediatricians, there was an absolute increase in the number of patients prescribed both doses of PEG 4000 from 2003 to 2007 in all children (aged 0-18 years), with 20,734 patients in 2003 and 58,691 in 2007 (test of trend $P=0.01$ ) (Table 3, Figure 3). There was a small increase among children aged 9-18 years over the 4 years available for the study, with 2818 patients in 2003 and 5242 in 2007 (test of trend $P=0.05$, Figure 3 ). The number of patients prescribed PEG 4000 was greater in the younger ( $0-8$ years) age group, with 17,916 patients in 2003, which increased after 2005 to 53,449 patients in 2007 (test of trend $P=0.001$ ) (Figure 3). The relative proportion of patients prescribed PEG 4000 in the 9-18 years age group declined from $13.6 \%$ in 2003 to $8.9 \%$ in 2007 , while the proportion in the $0-8$ years age group increased from $86.4 \%$ in 2003 to $91.1 \%$ in 2007 .

There was a decrease in the number of patients prescribed the $10 \mathrm{~g}$ dose, from 20,734 in 2003 to 8030 in 2007 (test of trend $P=0.03$ ) (Figure 4 ). The number of patients prescribed the $4 \mathrm{~g}$ dose was recorded as 0 from 2003 to 2004 (as this dose was unavailable until 2005), rising to 51,540 patients 
Table 2 Number of patients prescribed PEG 4000 (Forlax ${ }^{\circledR}$; Ipsen Pharma, Paris, France) among general practitioners by dose, gender, and year

\begin{tabular}{|c|c|c|c|c|c|c|c|c|c|c|c|c|c|c|c|}
\hline \multirow[t]{3}{*}{ Year } & \multicolumn{5}{|l|}{ All Forlax } & \multicolumn{5}{|c|}{ Forlax $10 \mathrm{~g}$} & \multicolumn{5}{|c|}{ Forlax $4 \mathrm{~g}^{*}$} \\
\hline & \multirow{2}{*}{$\begin{array}{l}\text { All } \\
\text { Total } \\
\text { number } \\
\text { of patients }\end{array}$} & \multicolumn{2}{|c|}{ Female } & \multicolumn{2}{|l|}{ Male } & \multirow{2}{*}{$\begin{array}{l}\text { Total } \\
\text { patients } \\
\text { Forlax } \\
10 \mathrm{~g}\end{array}$} & \multicolumn{2}{|c|}{ Female } & \multicolumn{2}{|l|}{ Male } & \multirow{2}{*}{$\begin{array}{l}\text { Total } \\
\text { patients } \\
\text { Forlax } \\
4 \mathrm{~g}\end{array}$} & \multicolumn{2}{|c|}{ Female } & \multicolumn{2}{|l|}{ Male } \\
\hline & & $\mathbf{n}$ & $\%$ & $\mathbf{n}$ & $\%$ & & n & $\%$ & $\mathbf{n}$ & $\%$ & & $\mathbf{n}$ & $\%$ & $\mathbf{n}$ & $\%$ \\
\hline 1997 & $\begin{array}{l}15,002 \\
(100 \%)\end{array}$ & $|0,56|$ & 70.4 & $444 I$ & 29.6 & 15,002 & $|0,56|$ & 70.4 & $444 I$ & 29.6 & - & - & - & - & - \\
\hline 1998 & $\begin{array}{l}19,482 \\
(100 \%)\end{array}$ & 13,618 & 69.9 & 5865 & 30.1 & 19,482 & 13,618 & 69.9 & 5865 & 30.1 & - & - & - & - & - \\
\hline 1999 & $\begin{array}{l}16,744 \\
(100 \%)\end{array}$ & 11,466 & 68.5 & 5278 & 31.5 & 16,744 & 11,466 & 68.5 & 5278 & 31.5 & - & - & - & - & - \\
\hline 2000 & $\begin{array}{l}24,381 \\
(100 \%)\end{array}$ & 17,879 & 73.3 & 6502 & 26.7 & 24,381 & 17,879 & 73.3 & 6502 & 26.7 & - & - & - & - & - \\
\hline 2001 & $\begin{array}{l}27,973 \\
(100 \%)\end{array}$ & 19,647 & 70.2 & 8326 & 29.8 & 27,973 & 19,647 & 70.2 & 8326 & 29.8 & - & - & - & - & - \\
\hline 2002 & $\begin{array}{l}29,481 \\
(100 \%)\end{array}$ & 19,674 & 66.7 & 9807 & 33.3 & $29,48 I$ & 19,674 & 66.7 & 9807 & 33.3 & - & - & - & - & - \\
\hline 2003 & $\begin{array}{l}37,495 \\
(100 \%)\end{array}$ & $25,7 \mid 4$ & 68.6 & $|I, 78|$ & 31.4 & 37,495 & $25,7 \mid 4$ & 68.6 & $|I, 78|$ & 31.4 & - & - & - & - & - \\
\hline 2004 & $\begin{array}{l}45,074 \\
(100 \%)\end{array}$ & 28,331 & 62.9 & 16,743 & 37.1 & 45,074 & 28,331 & 62.9 & 16,743 & 37.1 & - & - & - & - & - \\
\hline 2005 & $\begin{array}{l}74,043 \\
(100 \%)\end{array}$ & 45,172 & 61.0 & $28,87 \mid$ & 39.0 & 42,913 & 27,25 I & 63.5 & 15,663 & 36.5 & 31,817 & $18,4 \mid 3$ & 57.9 & 13,404 & 42.1 \\
\hline 2006 & $\begin{array}{l}128,348 \\
(100 \%)\end{array}$ & 75,077 & 58.5 & 53,270 & 41.5 & 44,651 & 28,919 & 64.8 & $|5,73|$ & 35.2 & 84,780 & 46,770 & 55.2 & 38,010 & 44.8 \\
\hline 2007 & $\begin{array}{l}133,952 \\
(100 \%)\end{array}$ & 79,081 & 59.0 & 54,872 & 41.0 & 47,053 & 29,673 & 63.1 & 17,380 & 36.9 & 88,454 & 50,256 & 56.8 & 38,198 & 43.2 \\
\hline
\end{tabular}

Notes: *Forlax $4 \mathrm{~g}$ launched in July 2005 in France; base for each year, patients aged 0-18 years treated at least once with Forlax $4 \mathrm{~g}$ and $10 \mathrm{~g}$ by general practitioners. Abbreviations: $n$, number; PEG, polyethylene glycol.

in 2007 (Table 2). This trend was statistically significant $(P=0.03)$ (Figure 4) and applied to females and males.

Among general practitioners in the database, out of 274,000 children who consulted in 2007, 10,309 had a diagnosis of constipation. Therefore, the prevalence of constipation in children aged $0-18$ years treated at least once with any laxative or enema (A06A ATC codes), or identified by a diagnosis of constipation in 2007 was $3.8 \%$ among general practitioners. Among pediatricians in the database, out of 102,345 children who consulted in 2007,4323 children

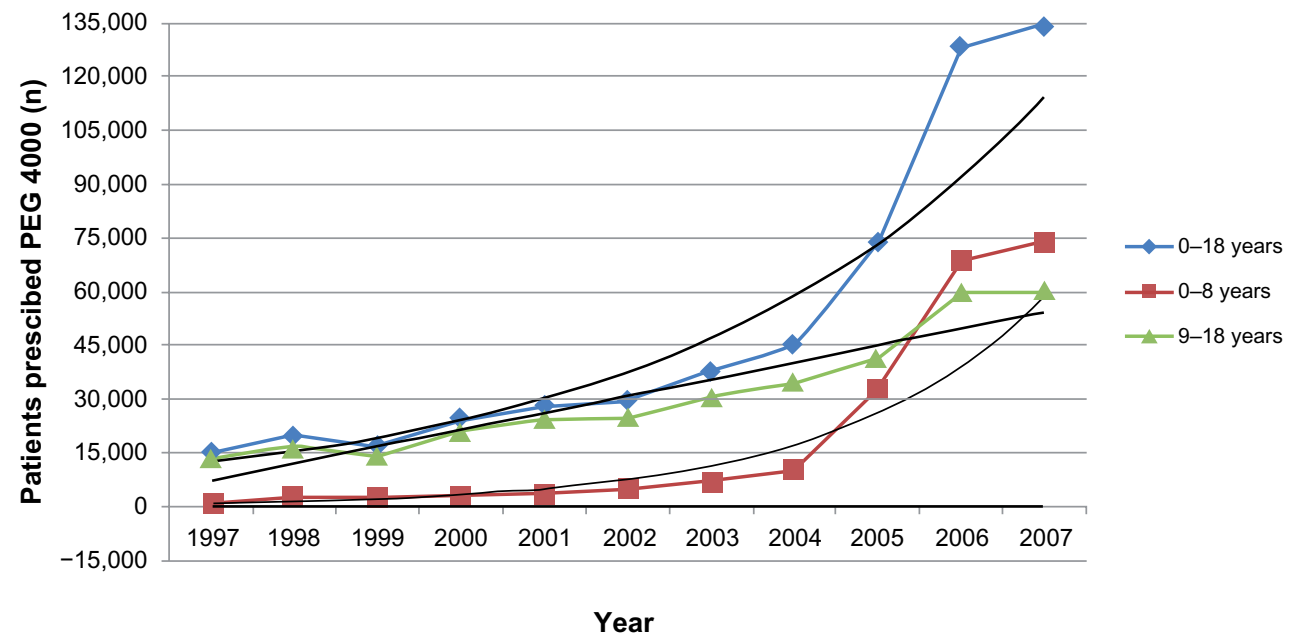

Figure I Number of patients prescribed PEG 4000 (Forlax ${ }^{\circledR}$; Ipsen Pharma, Paris, France) in children aged 0-8, 9-I8, and 0-18 years, by calendar year among general practitioners. Notes: Smooth lines are the modeled data. Model (exponential) for patients aged $0-18$ years: $y=9,895.2$ e0.22x; $(r 2=0.93) ; P<0.001$. Model (exponential) for patients aged 0-8 years: $y=647.0$ e0.4Ix; $(r 2=0.92) ; P<0.00$ I. Model (linear) for patients from 9 to I8 years old: $y=4,698.3 x+2,845.5 ;(r 2=0.88) ; P<0.00$ I.

Abbreviations: $n$, number; PEG, polyethylene glycol. 


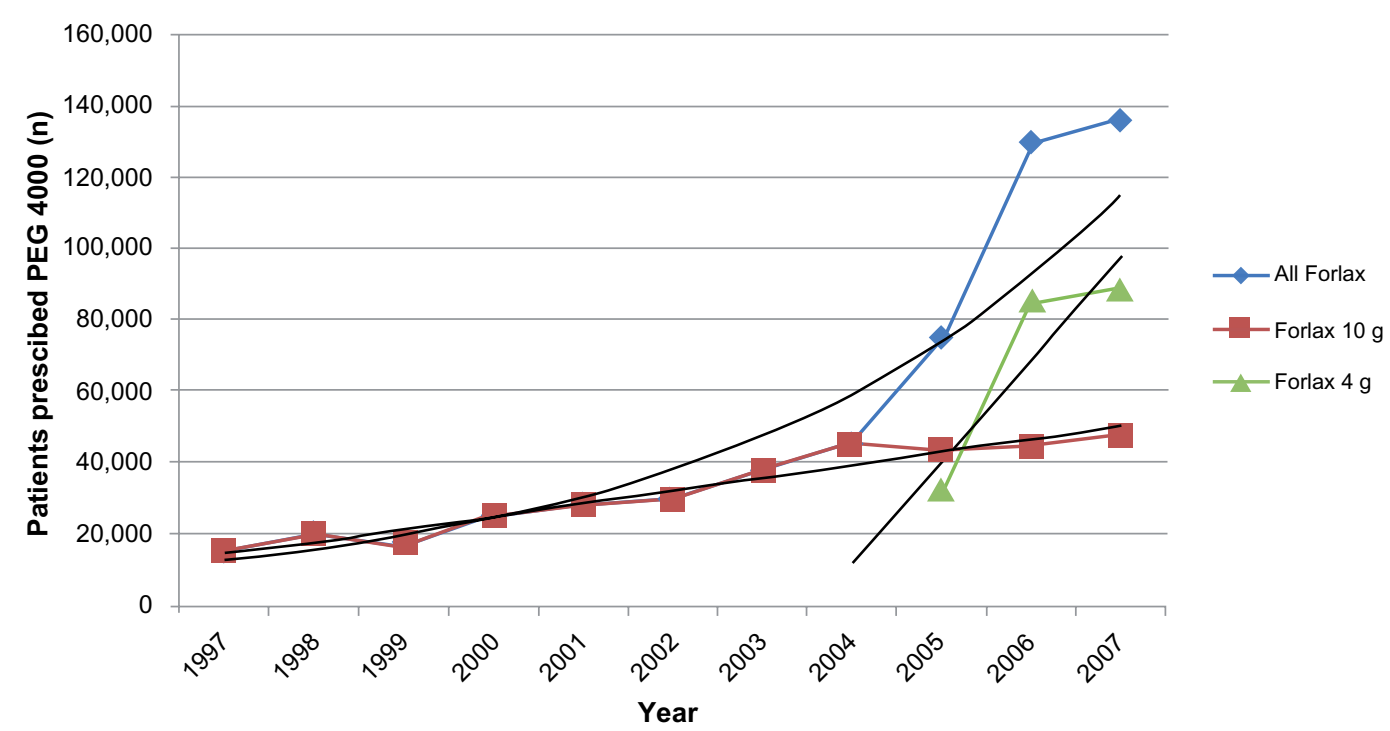

Figure 2 Number of patients prescribed the $4 \mathrm{~g}, 10 \mathrm{~g}$, and all doses of PEG 4000 (Forlax ${ }^{\circledR}$; Ipsen Pharma, Paris, France), by calendar year among general practitioners. Notes: Smooth lines are the modeled data. Model (exponential) for patients with prescriptions for all Forlax doses: $y=9,857.3 \mathrm{e} 0.22 \mathrm{x} ;(\mathrm{r} 2=0.93$ ); $P<0.00 \mathrm{I}$. Model (linear) for patients with prescription of Forlax $10 \mathrm{~g}: \mathrm{y}=3,485.6 \mathrm{x}+\mathrm{I0,550}$; $(\mathrm{r} 2=0.96) ; P<0.00 \mathrm{I}$. Model (linear) adjusted for patients with Forlax $4 \mathrm{~g}$ : $\mathrm{y}=28,3 \mathrm{I} 9 \mathrm{x}+\mathrm{II}, 7 \mathrm{I} 3$; $\mathrm{r} 2=0.80$.

Abbreviations: $\mathrm{n}$, number; PEG, polyethylene glycol.

had a diagnosis of constipation. Therefore, the prevalence of constipation in children aged $0-18$ years treated at least once with any laxative or enema (A06A ATC codes) or identified by a diagnosis of constipation in 2007 was $4.2 \%$ among pediatricians. The proportion of females conforming to this definition of constipation among general practitioners was $57.1 \%$ and $53.2 \%$ among pediatricians.

\section{Discussion}

The is the first study to describe the temporal pattern of utilization of hyperosmolar PEG laxatives, using patients prescribed Forlax as a representative agent for PEG use, in children aged $0-18$ years in France. The study demonstrates the large overall increase in the use of PEG laxatives from 1997 to 2007. There have been consistent increases in patients prescribed PEG laxatives by general practitioners, with less dramatic and less consistent patterns observed among pediatricians. The changes have reflected much greater use in younger children aged $0-8$ years by both general practitioners and pediatricians, and in females. However, for older children aged 9-18 years, general practitioners have prescribed an increasing number of patients PEG 4000, while the number of patients prescribed PEG 4000 by pediatricians has been almost static.

The statistical models have quantified the degree and pattern of changes in the use of hyperosmolar laxatives such as polyethylene glycol (PEG) 4000 and demonstrate that the increases over time have been statistically significant. Regression models using either simple linear or exponential regression models

Table 3 Number of patients prescribed PEG 4000 (Forlax ${ }^{\circledR}$; Ipsen Pharma, Paris, France) among pediatricians by dose, gender, and year

\begin{tabular}{|c|c|c|c|c|c|c|c|c|c|c|c|c|c|c|c|}
\hline \multirow[t]{3}{*}{ Year } & \multicolumn{5}{|l|}{ All Forlax } & \multicolumn{5}{|c|}{ Forlax $10 \mathrm{~g}$} & \multicolumn{5}{|c|}{ Forlax $4 \mathrm{~g}^{*}$} \\
\hline & \multirow{2}{*}{$\begin{array}{l}\text { All } \\
\text { Number } \\
\text { of subjects }\end{array}$} & \multicolumn{2}{|c|}{ Female } & \multicolumn{2}{|l|}{ Male } & \multirow{2}{*}{$\begin{array}{l}\text { Total } \\
\text { patients } \\
\text { Forlax } \\
10 \mathrm{~g}\end{array}$} & \multicolumn{2}{|c|}{ Female } & \multicolumn{2}{|l|}{ Male } & \multirow{2}{*}{$\begin{array}{l}\text { Total } \\
\text { patients } \\
\text { Forlax } \\
4 \mathrm{~g}\end{array}$} & \multicolumn{2}{|c|}{ Female } & \multicolumn{2}{|l|}{ Male } \\
\hline & & $\mathbf{n}$ & $\%$ & $\mathbf{n}$ & $\%$ & & $\mathbf{n}$ & $\%$ & $\mathbf{n}$ & $\%$ & & $\mathbf{n}$ & $\%$ & $\mathbf{n}$ & $\%$ \\
\hline 2003 & $\begin{array}{l}20,734 \\
(100 \%)\end{array}$ & 11,743 & 56.6 & 8991 & 43.4 & 20,734 & 11,743 & 56.6 & 8991 & 43.4 & - & - & - & - & - \\
\hline 2004 & $\begin{array}{l}21,981 \\
(100 \%)\end{array}$ & 11,465 & 52.2 & 10,516 & 47.8 & 21,981 & 11,465 & 52.2 & 10,516 & 47.8 & - & - & - & - & - \\
\hline 2005 & $\begin{array}{l}32,166 \\
(100 \%)\end{array}$ & 17,882 & 55.6 & 14,284 & 44.4 & 17,066 & 9461 & 55.4 & 7606 & 44.6 & 16,695 & 9164 & 54.9 & 7531 & 45.1 \\
\hline 2006 & $\begin{array}{l}54,298 \\
(100 \%)\end{array}$ & 28,285 & 52.1 & 26,013 & 47.9 & 9927 & 4874 & 49.1 & 5053 & 50.9 & 45,299 & 23,950 & 52.9 & 21,349 & 47.1 \\
\hline 2007 & $\begin{array}{l}58,691 \\
(100 \%)\end{array}$ & 32,179 & 54.8 & 26,513 & 45.2 & 8030 & 4060 & 50.6 & 3969 & 49.4 & 51,540 & 28,543 & 55.4 & 22,998 & 44.6 \\
\hline
\end{tabular}

Notes: *Forlax $4 \mathrm{~g}$ launched in July 2005 in France; base: for each year, patients aged 0-18 years treated at least once with Forlax $4 \mathrm{~g}$ and $10 \mathrm{~g}$ among paediatricians. Abbreviations: $n$, number; PEG, polyethylene glycol. 


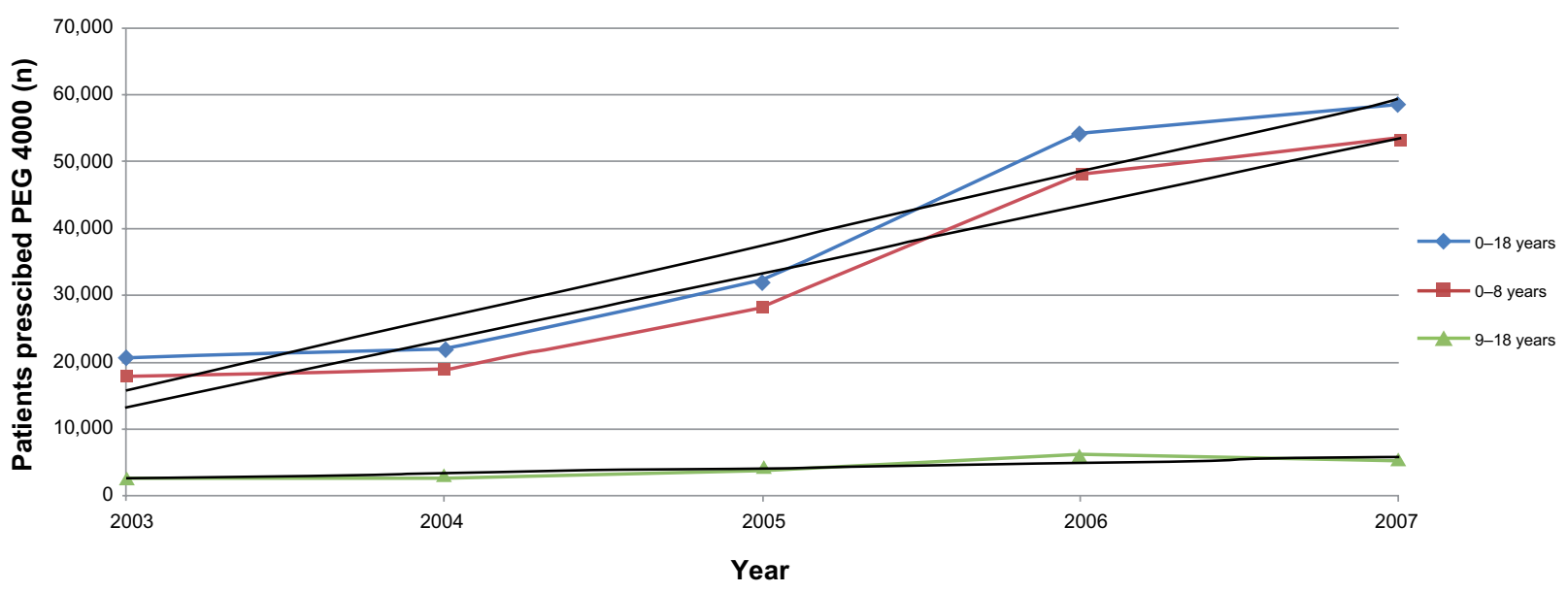

Figure 3 Number of patients prescribed PEG 4000 (Forlax ${ }^{\oplus}$; Ipsen Pharma, Paris, France) in children aged 0-8, 9-18, and 0-18 years, by calendar year among pediatricians. Notes: Smooth lines are the modeled data. Model (linear) adjusted for the increase in the number of patients aged 0-18 years with a prescription of Forlax: $y=10,823 x+15,928$; $r 2=0.91 ; P=0.01 \mathrm{I}$. Model (linear) adjusted for the increase in the number of patients aged $0-8$ years with a prescription of Forlax: $y=10,017 x+13,344 ; r 2=0.92 ; P=0.010$. Model (linear) adjusted for the increase in the number of patients aged 9-18 years with a prescription of Forlax: $y=805.3 x+2,584.1 ; r 2=0.77 ; P=0.049$.

Abbreviations: $\mathrm{n}$, number; PEG, polyethylene glycol.

were able to fit the data extremely well in all analyses except one, and provide robust and statistically significant estimates for the increments each year between 1997 to 2007 in patients prescribed PEG 4000 in $4 \mathrm{~g}$ and $10 \mathrm{~g}$ doses, by gender, and by age. Information for Forlax $4 \mathrm{~g}$ was the exception as there were data for only three time points from 2005 to 2007, which limited the power of the statistical models.

The study is the first to show and quantify off-label use of PEG laxatives in France and describe its influence on prescription patterns. Children aged 0-8 years have been prescribed the PEG 4000 trade-named product since 1997 by general practitioners and since 2003 by pediatricians (the earliest data available from the database). These prescriptions consisted of the $10 \mathrm{~g}$ dose as the $4 \mathrm{~g}$ dose was not launched in France until 2005. This represents off-label use, as the Summary of Product Characteristics for the $10 \mathrm{~g}$ dose states

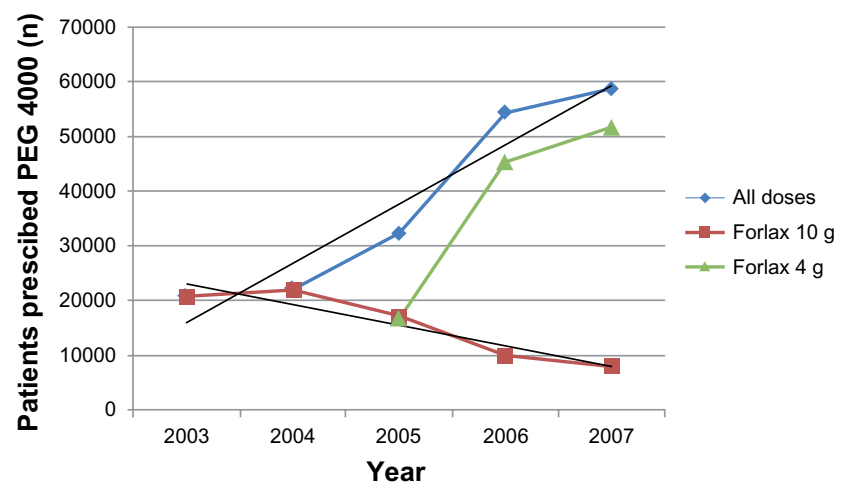

Figure 4 Number of patients prescribed the $4 \mathrm{~g}, 10 \mathrm{~g}$, and all doses of PEG 4000 (Forlax ${ }^{\circledR}$; Ipsen Pharma, Paris, France), by calendar year by pediatricians.

Notes: Smooth lines are the modeled data. Model (linear) adjusted for patients with a prescription of All Forlax doses: $y=10,823 x+5,104.5 ; r 2=0.91 ; P=0.011$. Model (linear) adjusted for patients with a prescription of Forlax I0 g: $y=3,746.3 x+26,786$; r2 $=0.88 ; P=0.017$.

Abbreviations: $n$, number; PEG, polyethylene glycol. that it is for use in children older than 8 years. ${ }^{18}$ However, the study was unable to determine whether parents were requested to adjust the administration of the $10 \mathrm{~g}$ dose during the preparation of the medication. Nevertheless, the dramatic and rapid increase in the number of patients aged $0-8$ years prescribed PEG 4000 laxatives, and in the $4 \mathrm{~g}$ dose among both general practitioners and pediatricians from the time the $4 \mathrm{~g}$ dose of Forlax was introduced (approved in 2005 for children from age 6 months to 8 years), ${ }^{19}$ revealed the large medical need for an approved laxative in this age group. The authors were not able to identify any studies that describe drug utilization of hyperosmolar laxatives in children in France with which to compare our results. However, prior to approval of the $4 \mathrm{~g}$ dose, there was a published clinical trial that used PEG 4000 as a comparator arm in young children, ${ }^{20}$ which may have influenced physicians to prescribe the $10 \mathrm{~g}$ dose of PEG 4000 as an off-label indication.

General practitioners have also been responsible for a large increase in the prescription of the $10 \mathrm{~g}$ dose, while pediatricians prescribed fewer patients the $10 \mathrm{~g}$ dose. This may reflect changing clinical practice, with pediatricians treating the more severe and younger cases, and general practitioners taking more responsibility for the less severe and older cases. The finding of a higher proportion of females prescribed PEG 4000 compared with males supports another study with nationally representative data from France in subjects $<30$ years old. ${ }^{16}$ The present study found that increases in prescriptions of laxatives to females were greater than in males between 1997 and 2007.

The overall patterns of results in our study are supported by prescribing patterns over time observed in the USA using a different methodology. Data from a nationally representative 
sample from the National Ambulatory Medical Care Survey, 1997 to 2006, a similar time period to our study, observed an increase from $15 \%$ to $42 \%$ in the proportion of visits due to constipation (derived from ICD-9 codes or prescription of a laxative) where a (unspecified) hyperosmolar laxative was prescribed in children $<18$ years old. ${ }^{3}$ Other age groups, including the $65+$ age group, did not record such large increases in the proportion of visits due to constipation where a (unspecified) hyperosmolar laxative was prescribed. ${ }^{3}$ Thus, hyperosmolar laxatives were more likely to be prescribed to children than adults, reinforcing the importance of the findings of our study for public health. The higher use of PEG laxatives in children aged 0-8 years, after approval in 2005 of the $4 \mathrm{~g}$ dose of Forlax for children from age 6 months to 8 years, compared with children aged 9-18 years, is supported by the higher prevalence of constipation in younger children in the study by Liem et al. ${ }^{16}$ Although differences in methodology, sampling frames, and populations sampled make direct comparisons between studies difficult, the trends over time observed within each study are more reliable.

Constipation in France among children aged $0-18$ years is common and has a prevalence that is approximately $4 \%$. This figure is a little higher than the prevalence of $1.1 \%$ found in a nationally representative sample of visits to physicians by US children aged 0-18 years, where the diagnosis was based on ICD-9 codes or laxative prescription records. ${ }^{16}$ The use of recorded ICD-9 codes may be the explanation for the lower prevalence figure in the US study compared with the present study. Reassuringly, the US sample also provided a figure of $51 \%$ for constipation in females, ${ }^{16}$ which is not very different to the $57 \%$ observed in this study. This study and the US study ${ }^{16}$ are at odds with prevalence estimates obtained from a cross-sectional survey of nationally representative samples of subjects which found that the proportion of subjects under 30 years old reporting constipation (from a questionnaire) was $12 \%$ in France and $13 \%$ in the USA. ${ }^{15}$ The use of a representative sample to detect constipation in patients who do not consult their physician for constipation and the looser criteria to define constipation than that used by physicians are likely explanations for the much higher prevalence rates of constipation in the study. ${ }^{15}$

There are several limitations to the present study, which used data collected routinely for clinical care. By using a single trade-named product (Forlax) as an indicator of PEG 4000 use, the utilization of PEG 4000 laxatives in children may have been underestimated. Clinical opinion indicated that most children were given this product as the preferred PEG 4000 during the years of the study. However, this study did not have independent prescription or sales data to verify this assumption. Also, other
PEGs such as PEG 4000 with electrolytes, and PEG 3350 with and without electrolytes would underestimate the degree of use of PEG laxatives for constipation in children, as represented by a single trade-named prescription product. Other non-PEG laxatives were also not included and will likewise be a source of underestimation of laxative use. Nonetheless, the absolute utilization rates and trends for the particular PEG 4000 in this study remain valid, though they may not describe the entire picture of laxative use for constipation in France. Patient medical records in the database refer to unique patients except when patients move between physician practices and may be double counted. Thus, although patients are able to change general practitioner and pediatrician, which could result in a loss of patients and some double counting, patient movement among children is low. Patient movement between physicians may pose problems for cohort analyses, but as this study used cross-sectional analyses based on the subjects in each practice in each year, this source of error would have been minimal and unlikely to affect trends over time. Since data are collected directly by the physicians and uploaded anonymously, it is not possible to refer back to patients' files and perform site quality control and validation of the diagnosis of constipation. The comparable figure of $1.1 \%$ constipation (using ICD-codes and laxative prescriptions) in a nationally representative sample of visits to physicians in the USA indicates that the diagnosis for constipation in this study was appropriate. However, the quality of the information from daily clinical practice is assessed by administrative quality indicators. This and the fact that all data, which have already been collected without any influence from investigators (as may occur in protocol-driven observational studies of drug utilization), come from routine clinical practice also lends credibility to the data. The data from pediatricians and the $4 \mathrm{~g}$ dose may be subject to overfitting of the models as there were only 3 or 4 years of data available. However, given similar trends over a longer period of time from general practitioners, the data from pediatricians are consistent and, hence, likely to be reasonably robust. Of course, the regression models are based on the data used and caution should be exercised in extrapolation of these models beyond the years studied or to other data sets. Nonetheless, they provide a comparison for future studies of laxative utilization.

Information on the indication for the prescription was not requested and it is assumed that most prescriptions were for constipation. Bowel cleansing may have accounted for a small number of prescriptions, more among pediatricians than among general practitioners, but this is likely to be an insignificant proportion and would have altered the results only marginally. Furthermore, it is not likely to have affected the observed trends over time, by age groups or gender. 


\section{Conclusion}

This study has found large absolute levels of utilization of PEG 4000 laxatives and increasing use over time in younger and older children, among general practitioners and pediatricians in France. These findings may highlight an important public health issue to address for policy makers, clinicians, and parents. The results highlight the need for studies in other European countries to describe patterns and trends in utilization of different laxatives. Further research should be encouraged in this relatively neglected area to evaluate whether the prescribing is based on evidence-based guidelines, ${ }^{21}$ given that general practitioners are prescribing PEG laxatives for constipation more than previously, and whether outcomes have improved.

\section{Contributors}

NQ designed and supervised the study, revised the analyses, and drafted and revised the manuscript. IM conducted the statistical analysis and revised the manuscript. The LPD data were provided by Cegedim Strategic Data, the database provider in France.

NQ is the guarantor of the study.

\section{Acknowledgment}

Thanks are owed to Daniel Prieto at Casen-Fleet SLU Laboratories for commissioning the study and its publication.

\section{Disclosure}

The study was financed by Casen-Fleet SLU Laboratories, Madrid, Spain. NQ heads OXON Epidemiology, which is a contract research organization that conducts research for health sector companies. IM is an employee of OXON Epidemiology. Casen-Fleet SLU Laboratories are developing a PEG 4000 laxative.

\section{References}

1. Peppas G, Alexiou VG, Mourtzoukou E, Falagas ME. Epidemiology of constipation in Europe and Oceania: a systematic review. $B M C$ Gastroenterol. 2008;8:5.

2. Van den Berg MM, Benninga MA, Di Lorenzo C. Epidemiology of childhood constipation: a systematic review. Am J Gastroenterol. 2006; 101(10):2401-2409.

3. Trinkley KE, Porter K, Nahata MC. Prescribing patterns for the outpatient treatment of constipation in the United States. Dig Dis Sci. 2010;55(12):3514-3520.
4. Van Ginkel R, Reitsma JB, Buller HA, van Wijk MP, Taminiau JA, Benninga MA. Childhood constipation: longitudinal follow-up beyond puberty. Gastroenterology. 2003;125(2):357-363.

5. Mousa HM, van den Berg MM, Caniano DA, Hogan M, Di Lorenzo C, Hayes J. Cecostomy in children with defecation disorders. Dig Dis Sci. 2006;51(1):154-160.

6. Youssef NN, Langseder AL, Verga BJ, Mones RL, Rosh JR. Chronic childhood constipation is associated with impaired quality of life: a casecontrolled study. J Pediatr Gastroenterol Nutr. 2005;41(1):56-60.

7. Johanson JF, Sonnenberg A, Koch TR. Clinical epidemiology of chronic constipation. J Clin Gastroenterol. 1989;11(5):525-536.

8. Locke GR III, Pemberton JH, Phillips SF. AGA technical review on constipation. Gastroenterology. 2000;119(6):1766-1778.

9. Higgins PDR, Johanson JF. Epidemiology of constipation in North America: a systematic review. Am J Gastroenterol. 2004;99(4): 750-759.

10. Talley NJ. Definitions, epidemiology, and impact of chronic constipation. Rev Gastroenterol Disord. 2004;4(Suppl 2):S3-S10.

11. Brandt LJ, Prather CM, Quigley EMM, Schiller LR, Schoenfeld P, Talley NJ. Systematic review on the management of chronic constipation in North America. Am J Gastroenterol. 2005;100(Suppl 1):S5-S21.

12. Curtin F, Morabia A, Bernstein M, Dederding J-P. A population survey of bowel habits in urban Swiss men. Eur J Pub Health. 1998;8: 170-175.

13. Drossman DA, Sandler RS, McKee DC, Lovitz AJ. Bowel patterns among subjects not seeking health care. Use of a questionnaire to identify a population with bowel dysfunction. Gastroenterology. 1982; 83(3):529-534

14. Ho KY, Kang JY, Seo A. Prevalence of gastrointestinal symptoms in a multiracial Asian population, with particular reference to reflux-type symptoms. Am J Gastroenterol. 1998;93(10):1816-1822.

15. Wald A, Scarpignato C, Mueller-Lissner S, et al. A multinational survey of prevalence and patterns of laxative use among adults with self-defined constipation. Aliment Pharmacol Ther. 2008;28(7):917-930.

16. Liem O, Harman J, Benninga M, Kelleher K, Mousa H, Di Lorenzo C. Health utilization and cost impact of childhood constipation in the United States. J Pediatr. 2009;154(2):258-262.

17. Ekins-Daukes S, Helms PJ, Simpson CR, Taylor MW, McLay JS. Offlabel prescribing to children in primary care: retrospective observational study. Eur J Clin Pharmacol. 2004;60:349-353.

18. AFSSAPS. [Summary of Product Characteristics for Forlax ${ }^{\mathcal{O}} 10 \mathrm{~g}$.] [French.] Paris: AFSSAPS; 2010 [updated Oct 22 2010]. Available from http://afssaps prd.afssaps.fr/php/ecodex/frames.php?specid=69 298346\&typedoc=R\&ref=R0180198htm. Accessed March 21, 2011.

19. AFSSAPS. [Summary of Product Characteristics for Forlax ${ }^{\circ} 4$ g.] [French.] Paris: AFSSAPS; 2010 [updated Oct 22 2010]. Available from http://afssapsprd.afssaps.fr/php/ecodex/frames.php?specid=691 98794\&typedoc=R\&ref=R0180199.htm. Accessed March 21, 2011.

20. Dupont C, Leluyer B, Maamri N, et al. Double-blind randomized evaluation of clinical and biological tolerance of polyethylene glycol 4000 versus lactulose in constipated children. J Pediatr Gastroenterol Nutr. 2005;41(5):625-633.

21. Constipation Guideline Committee of the North American Society for Pediatric Gastroenterology. Evaluation and treatment of constipation in infants and children: recommendations of the North American Society for Pediatric Gastroenterology, Hepatology and Nutrition. J Pediatr Gastroenterol Nutr. 2006;43(3):e1-e13.
Clinical and Experimental Gastroenterology

\section{Publish your work in this journal}

Clinical and Experimental Gastroenterology is an international, peerreviewed, open access journal, publishing all aspects of gastroenterology in the clinic and laboratory, including: Pathology, pathophysiology of gastrointestinal disease; Investigation and treatment of gastointestinal disease; Pharmacology of drugs used in the alimentary tract;

\section{Dovepress}

Immunology/genetics/genomics related to gastrointestinal disease. This journal is indexed on CAS. The manuscript management system is completely online and includes a very quick and fair peer-review system. Visit http://www.dovepress.com/testimonials.php to read real quotes from published authors. 